\title{
Shock equation of state of basalt
}

\author{
Toshimori Sekine ${ }^{1}$, Takamichi Kobayashi ${ }^{1}$, Mineyuki Nishio $^{2}$, and Eiichi Takahashi ${ }^{2}$ \\ ${ }^{1}$ National Institute for Materials Science, Namiki 1-1, Tsukuba 305-0044, Japan \\ ${ }^{2}$ Department of Earth and Planetary Sciences, Tokyo Institute of Technology, Meguro-ku, Tokyo 152-8551, Japan
}

(Received March 25, 2008; Revised July 2, 2008; Accepted July 10, 2008; Online published October 15, 2008)

\begin{abstract}
Detailed wave profiles for Kinosaki basalt at pressures up to $25 \mathrm{GPa}$ are measured using a laser velocity interferometer in order to determine the dynamic properties. The results indicate a Hugoniot elastic limit of $\sim 2 \mathrm{GPa}$ and a relationship between shock velocity $\left(U_{\mathrm{s}}\right)$ and particle velocity $\left(U_{\mathrm{p}}\right)$ approximated by $U_{\mathrm{s}}(\mathrm{km} / \mathrm{s})=$ $3.5+1.3 U_{\mathrm{p}}(\mathrm{km} / \mathrm{s})$ in the low-pressure plastic region $\left(U_{\mathrm{p}}\right.$ below $\left.\sim 4 \mathrm{~km} / \mathrm{s}\right)$. These data are compared with the known data for rocks with basaltic compositions, and tensile strength of the basaltic rocks was found to be about one tenth of that of compression strength.
\end{abstract}

Key words: Shock equation of state, basalt, dynamic behavior, Hugoniot, VISAR.

\section{Introduction}

Basalt is one of the most typical rocks on the Earth. Comprehensive studies on basalts are available in the book by the Basaltic Volcanism Study Project (1981). Basalts are known to be distributed widely, not only on the Earth but also on the surfaces of Moon and other terrestrial planets, and to be a major component of some of the stony meteorites. Basalts have also been used experimentally as an analog for planetesimals. In the current standard model of the early solar system, collisions among planetesimals occur repeatedly, and planetesimals grow into planetary bodies. In order to understand the impact process on planetary bodies and the growth mechanism of planetesimals in the early solar system, we need to know the basic properties of rocks at the time of impact.

There are several sets of Hugoniot data available for rocks with basaltic compositions. Ahrens and Gregson (1964), based on the inclined mirror method, measured the Hugoniot of Vacavill basalt in relatively low-pressure region and gave a Huginot elastic limit (HEL) of 4-5 GPa. Jones et al. (1968) measured the Hugoniot of the Vacavill basalt up to $\sim 200 \mathrm{GPa}$. The composition (by wt $\%$ ) is $\mathrm{SiO}_{2}$, 50.3; $\mathrm{TiO}_{2}, 2.4 ; \mathrm{Al}_{2} \mathrm{O}_{3}, 13.8 ; \mathrm{Fe}_{2} \mathrm{O}_{3}, 3.5 ; \mathrm{FeO}, 9.1 ; \mathrm{MnO}$, 0.24; $\mathrm{MgO}, 4.4 ; \mathrm{CaO}, 7.7 ; \mathrm{Na}_{2} \mathrm{O}, 3.3 ; \mathrm{K}_{2} \mathrm{O}, 1.6 ; \mathrm{P}_{2} \mathrm{O}_{5}, 1.2$; $\mathrm{H}_{2} \mathrm{O}, 2.5 ; \mathrm{CO}_{2}, 0.05$; with a total of 100.1 (van Thiel, 1977). Nakazawa et al. (1997) employed piezoresistive manganin gauges sandwiched between Kinosaki basalt disks to measure pressure and shock velocity simultaneously and subsequently calculated the particle velocity by the RankineHugoniot equations. According to their data, the shock velocity-particle velocity relation up to about $50 \mathrm{GPa}$ is approximated separately by three linear equations as a function of particle velocity, and they estimated a HEL of $5 \mathrm{GPa}$ for Kinosaki basalt. Although there seems to be a good

Copyright (c) The Society of Geomagnetism and Earth, Planetary and Space Sciences (SGEPSS); The Seismological Society of Japan; The Volcanological Society of Japan; The Geodetic Society of Japan; The Japanese Society for Planetary Sciences; TERRAPUB. agreement in the high-pressure region (>20 GPa) for the Hugoniot of rocks with basaltic compositions, the data in the lower pressure region are still quite divergent. This is partially because basalts have pores to some degree $(\sim 5 \%)$ and slightly differ in density and sound velocity. It is important to understand the dynamic behavior of basalt in the low-pressure region in order to estimate the basic properties, such as strength parameters, that are required for applications of laboratory results to planetary collision events and cratering processes. Hugoniot elastic limit is closely related to the shear strength, and it is not well determined in basaltic rocks. This paper reports the detailed wave profiles to determine the HEL and Hugoniot at relatively lowpressure regions.

\section{Experimental Procedure}

We used the same Kinosaki basalt as Nakazawa et al. (1997). The chemical composition (by wt\%) is $\mathrm{SiO}_{2}$, 49.49; $\mathrm{TiO}_{2}, 2.17 ; \mathrm{Al}_{2} \mathrm{O}_{3}, 17.12 ; \mathrm{Fe}_{2} \mathrm{O}_{3}, 1.05 ; \mathrm{FeO}, 8.54$; $\mathrm{MnO}, 0.15 ; \mathrm{MgO}, 6.64 ; \mathrm{CaO}, 8.43 ; \mathrm{Na}_{2} \mathrm{O}, 3.63 ; \mathrm{K}_{2} \mathrm{O}$, $1.73 ; \mathrm{P}_{2} \mathrm{O}_{5}, 0.71$; with a total of 99.56 (Genbudo Research Group, 1991). The basalt consists of $\sim 5 \mathrm{vol} \%$ phenocrysts of olivine and plagioclase and $\sim 95$ vol\% groundmass. This composition is quite similar to that of Vacavill basalt. The sound velocity data of Kinosaki basalt indicate a range of $4.10-4.64 \mathrm{~km} / \mathrm{s}$ (Nakazawa et al., 1997) and $4.15-5.15 \mathrm{~km} / \mathrm{s}$ (Nakazawa et al., 2002) for longitudinal wave $\left(C_{l}\right)$ and $2.60-2.92 \mathrm{~km} / \mathrm{s}$ (Nakazawa et al., 1997) and $2.25-3.00 \mathrm{~km} / \mathrm{s}$ (Nakazawa et al., 2002) for shear wave $\left(C_{s}\right)$. Disks ( $\sim 30 \mathrm{~mm}$ in diameter and $\sim 3 \mathrm{~mm}$ thick) were cut and set on driver plates (stainless steel 304, $40 \mathrm{~mm}$ in diameter and $\sim 1 \mathrm{~mm}$ thick). The initial density of each disk was measured to be $2.70 \pm 0.04 \mathrm{~g} / \mathrm{cm}^{3}$. Figure 1 illustrates the target and experimental setup.

We used a laser velocity interferometer (VISAR) to detect the detailed wave profiles, which give time-resolved shock wave structures (Barker and Hollenbach, 1972; Barker, 1998). At the low-pressure region, a two-wave 
Table 1 . Summary of $U_{\mathrm{s}}-U_{\mathrm{p}}$ relations used in the present study.

\begin{tabular}{lcccl}
\hline Material $^{\mathrm{a}}$ & Density $\left(\mathrm{g} / \mathrm{cm}^{3}\right)$ & \multicolumn{2}{c}{$U_{\mathrm{s}}(\mathrm{km} / \mathrm{s})=C+S U_{\mathrm{p}}(\mathrm{km} / \mathrm{s})^{\mathrm{b}}$} & \multirow{2}{*}{ Ref. } \\
\cline { 3 - 4 } & & $C$ & $S$ & \\
\hline FQz & 2.23 & 5.264 & -0.114 & Marsh $(1980)$ \\
LiF & 2.638 & 5.15 & 1.35 & Marsh (1980) \\
PMMA & 1.186 & 2.6 & 1.51 & Marsh (1980) \\
SP-30 & 0.11 & -0.1 & 1.16 & Holmes and See (1992) \\
& & & & Nikolaev et al. (2000) \\
Basalt & 2.70 & 3.5 & 1.3 & Present study \\
Stainless steel 304 & 7.89 & 4.58 & 1.49 & Marsh (1980) \\
Tungsten & 19.2 & 4.04 & 1.23 & Marsh (1980) \\
\hline
\end{tabular}

${ }^{\mathrm{a}} \mathrm{FQz}$, Fused quartz; LiF, lithium fluoride; SP-30, silica aerogel; PMMA, polymethylmethacrylate. ${ }^{\mathrm{b}} U_{\mathrm{s}}$, Shock velocity; $U_{\mathrm{p}}$, particle velocity.

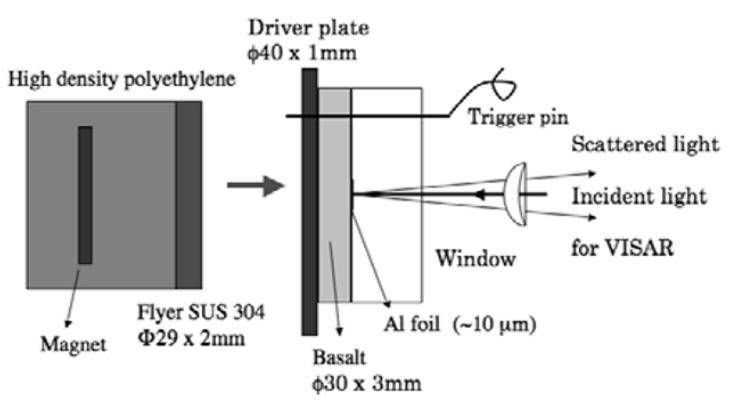

Fig. 1. Schematic illustration of experimental setup. A projectile is accelerated by a $30-\mathrm{mm}$-bore propellant gun. Driver plate is stainless steel 304.

structure consisting of elastic and plastic waves can be generated by a plane impact, and the VISAR signal will show their arrival times as a function of the sample thickness. These two shock waves travel at different velocities of longitudinal and bulk sound waves, respectively. The corresponding particle velocities in the basalt sample were measured through a window material. A thin aluminum foil $(\sim 10 \mu \mathrm{m})$ was put as a reflector between basalt and window. Polymethylmethacrylate (PMMA), fused quartz (FQz), lithium fluoride (LiF), and silica aerogel (SP-30) with a density of $0.11 \mathrm{~g} / \mathrm{cm}^{3}$ were used as windows. Their Hugoniots are available and summarized in Table 1. The silica aerogel was provided from the Matsushita Electric Industry Ltd., and its transparency is about $90 \%$ for a thickness of $10 \mathrm{~mm}$ at a wavelength of $532 \mathrm{~nm}$. The shock impedance of $\mathrm{Al}$ is a little higher than that of $\mathrm{LiF}$, and basalt has an intermediate shock impedance between LiF and FQz.

\section{Results}

We observed nine VISAR profiles at impact velocities of $0.6-1.9 \mathrm{~km} / \mathrm{s}$ and at pressures of 4-25 GPa. Table 2 lists the experimental conditions and results. Figure 2 illustrates six profiles observed at impact velocities of up to $1.22 \mathrm{~km} / \mathrm{s}$. These profiles indicate two-wave structures, although the observed first precursor wave is very weak. The precursor wave displays a slow rising-time and does not seem to come from the reflection by the aluminum because the expected travel time is about $2 \mathrm{~ns}$, and repeated back and forward times will sum at most $10 \mathrm{~ns}$. The precursors can be assigned as the HEL of either $\mathrm{Al}$ or stainless steel from the

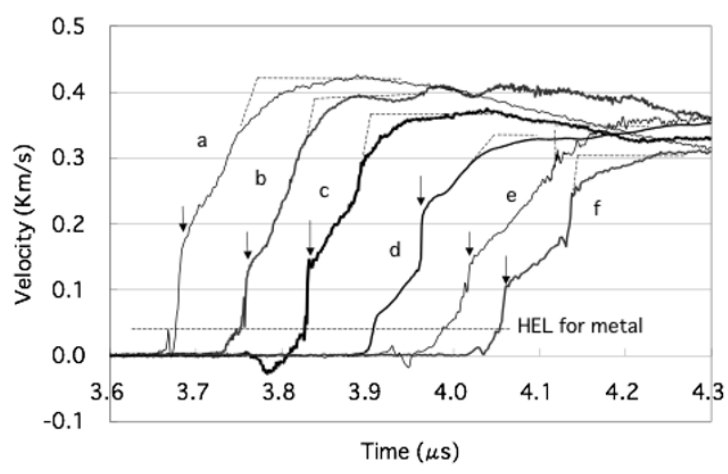

Fig. 2. Observed VISAR profiles for Kinosaki basalt at impact velocities up to $1.22 \mathrm{~km} / \mathrm{s}$. (a) For shot 1385, (b) for shot 1354, (c) for shot 1357, (d) for shot 1353, (e) for shot 1384, (f) for shot 1452. Arrows indicate the elastic wave arrival, and the broken lines are the trace for estimation of the plastic wave arrival. Some of these profiles need correction for fringe loss to determine the final velocity (see Table 2).

weakness $(\sim 0.5-1 \mathrm{GPa})$, as inferred from their HEL values (Meyers, 1994). The precursor wave is too weak for the HEL of the basalt, and we take the fast rising wave as the HEL for the basalt. The elastic waves in the VISAR profiles show fast rising relatively and the plastic waves with various risings. The arrival time for the plastic wave is taken as a crossing of the rising line and peak particle velocity on a VISAR profile, as illustrated by dashed lines in Fig. 2. The obtained time difference between the elastic wave and the plastic wave is listed in Table 2. Here, the first shock velocity is assumed to travel as the longitudinal wave $(4.6 \pm 0.5 \mathrm{~km} / \mathrm{s}$ from Nakazawa et al., 1997, 2002) because there is little pressure effect, and the second shock wave runs at a bulk sound velocity. The average time normalized to sample thickness is $0.030(\mu \mathrm{s} / \mathrm{mm})$, and the second shock velocity is calculated to be $4.1 \pm 0.4 \mathrm{~km} / \mathrm{s}$ based on a range of longitudinal wave velocity of the Kinosaki basalt (Nakazawa et al., 1997, 2002). The observed particle velocity of the first shock is $0.11-0.22 \mathrm{~km} / \mathrm{s}$ (Table 2). These results indicate that a HEL is fixed at $\sim 2 \mathrm{GPa}$ and $2.80 \mathrm{~g} / \mathrm{cm}^{3}$. After taking the HEL state into account, the final shock state for the experiments displaying the two-wave structures is calculated and listed in Table 2. Based on the results of the lowest pressure experiments (\#1353 and \#1357), the final shock states are at $4.1 \pm 0.4 \mathrm{~km} / \mathrm{s}$ for $U_{\mathrm{s}}$ and $0.35-0.37 \mathrm{~km} / \mathrm{s}$ for $U_{\mathrm{p}}$ (assuming the same impedance as that of FQz). This 
Table 2. Summary of experimental results on Kinosaki basalt. Initial density is $2.70 \pm 0.04 \mathrm{~g} / \mathrm{cm}^{3}$.

\begin{tabular}{|c|c|c|c|c|c|c|c|c|c|}
\hline Shot\# & $\begin{array}{c}\text { Thickness } \\
L(\mathrm{~mm})\end{array}$ & $\begin{array}{c}\text { Impact } \\
\text { velocity }^{\mathrm{a}}(\mathrm{km} / \mathrm{s})\end{array}$ & $\begin{array}{l}\Delta t^{\mathrm{b}} \\
\text { (ns) }\end{array}$ & $\begin{array}{c}\Delta t / L \\
(\mu \mathrm{s} / \mathrm{mm})\end{array}$ & $\begin{array}{l}1^{\text {st }} U_{\mathrm{p}} \\
(\mathrm{km} / \mathrm{s})\end{array}$ & $\begin{array}{c}\text { Final } U_{\mathrm{p}} \\
(\mathrm{km} / \mathrm{s})\end{array}$ & $\begin{array}{c}U_{\mathrm{s}} \\
(\mathrm{km} / \mathrm{s})\end{array}$ & $\begin{array}{c}P \\
(\mathrm{GPa})\end{array}$ & $\begin{array}{l}\text { Density } \\
\left(\mathrm{g} / \mathrm{cm}^{3}\right)\end{array}$ \\
\hline \multirow[t]{2}{*}{1353} & $2.90(0.01)$ & $(0.6)$ & 80 & 0.028 & 0.22 & 0.34 (FQz) & 5.23 & 3.96 & \\
\hline & & & & & & $0.35(\mathrm{~B})$ & 3.96 & 4.08 & 2.96 \\
\hline \multirow[t]{2}{*}{1357} & $2.97(0.01)$ & 0.614 & 80 & 0.027 & 0.14 & 0.37 (FQz) & 5.22 & 4.31 & \\
\hline & & & & & & $0.38(\mathrm{~B})$ & 4.00 & 4.42 & 2.98 \\
\hline \multirow[t]{2}{*}{1384} & $3.10(0.01)$ & 0.679 & 110 & 0.035 & 0.15 & 0.72 (PMMA) & 3.68 & 3.13 & \\
\hline & & & & & & $0.51(\mathrm{~B})$ & 4.16 & 5.93 & 3.08 \\
\hline \multirow[t]{2}{*}{1452} & $3.13(0.01)$ & 0.680 & 90 & 0.029 & 0.11 & $0.45(\mathrm{LiF})$ & 5.76 & 6.84 & \\
\hline & & & & & & $0.52(\mathrm{~B})$ & 4.18 & 6.08 & 3.08 \\
\hline \multirow[t]{2}{*}{1354} & $2.85(0.02)$ & 0.722 & 90 & 0.031 & 0.13 & $0.58(\mathrm{FQz})$ & 5.20 & 6.73 & \\
\hline & & & & & & $0.58(\mathrm{~B})$ & 4.26 & 6.88 & 3.13 \\
\hline \multirow[t]{2}{*}{1385} & $2.93(0.02)$ & 1.22 & 90 & 0.031 & 0.15 & $1.86(\mathrm{SP})$ & 2.06 & 0.42 & \\
\hline & & & & & & $0.95(\mathrm{~B})$ & 4.74 & 12.2 & 3.38 \\
\hline \multirow[t]{2}{*}{1381} & $2.79(0.03)$ & 1.28 & & Not observed & & 1.05 (FQz) & 5.14 & 12.0 & \\
\hline & & & & & & $1.00(\mathrm{~B})$ & 4.79 & 12.9 & 3.41 \\
\hline \multirow[t]{2}{*}{1382} & $2.96(0.03)$ & 1.78 & & Not observed & & 1.35 (FQz) & 5.11 & 15.4 & \\
\hline & & & & & & $1.25(\mathrm{~B})$ & 5.12 & 17.3 & 3.57 \\
\hline \multirow[t]{2}{*}{1386} & $3.03(0.01)$ & $1.89(\mathrm{~W})$ & & Not observed & & $1.45(\mathrm{LiF})$ & 7.11 & 27.2 & \\
\hline & & & & & & $1.60(\mathrm{~B})$ & 5.58 & 24.1 & 3.79 \\
\hline
\end{tabular}

${ }^{\mathrm{a}}$ Impact velocity was measured in each shot, except for \#1353 in which it was estimated based on the amount of propellant. ${ }^{\mathrm{b}} \Delta t$ was measured as the arrival time difference between elastic and plastic waves. For the two-wave structure profiles, the final particle velocity $\left(U_{\mathrm{p}}\right)$ for basalt $(\mathrm{B})$ was calculated based on the impedance match method using the measured $U_{\mathrm{p}}$ and the $U_{\mathrm{s}}-U_{\mathrm{p}}$ relations given in Table 1 . The first shock state (HEL) is fixed at 2 GPa and $2.80 \mathrm{~g} / \mathrm{cm}^{3}$ using a value of $0.15 \mathrm{~km} / \mathrm{s}$ for $U_{\mathrm{p}}$.
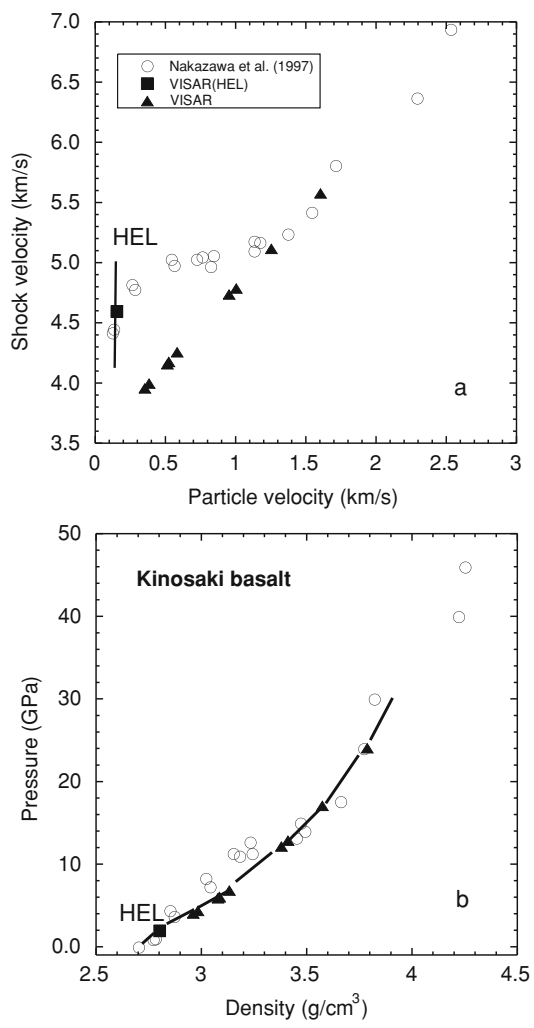

Fig. 3. Hugoniot for Kinosaki basalt. (a) $U_{\mathrm{s}}-U_{\mathrm{p}}$ relations and (b) pressure-density relation. Circles from Nakazawa et al. (1997); triangles from the present study.

point is closely located on a linear relationship of $U_{\mathrm{s}}(\mathrm{km} / \mathrm{s})$ $=3.5+1.3 U_{\mathrm{p}}(\mathrm{km} / \mathrm{s})$, and we used the relationship to calculate $U_{\mathrm{s}}$ from the observed $U_{\mathrm{p}}$ in each shot (Table 2). The typical zero-pressure bulk modulus of the Kinosaki basalt

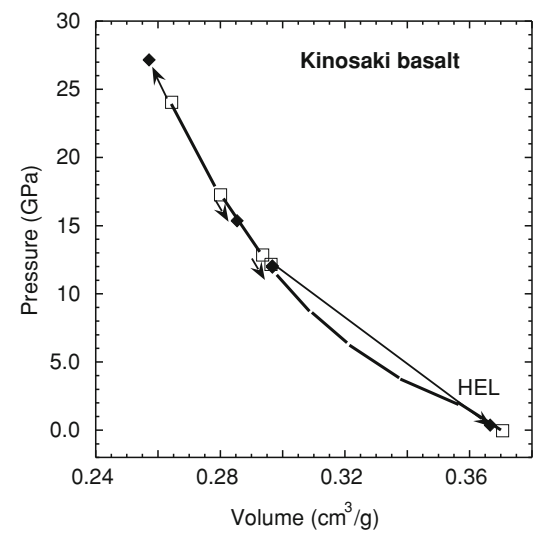

Fig. 4. Pressure-volume relation measured by VISAR for Kinosaki basalt, including the release and recompression states from the primary Hugoniot states. Arrows connect the points of Hugoniot and partial release (or recompressed) states, but do not indicate the actual paths.

( $35 \pm 10 \mathrm{GPa}$, Nakazawa et al., 2002) is also consistent with the new $U_{\mathrm{s}}-U_{\mathrm{p}}$ relation, but not with the equation $U_{\mathrm{s}}(\mathrm{km} / \mathrm{s})$ $=3+1.5 U_{\mathrm{p}}(\mathrm{km} / \mathrm{s})$ given by Nakazawa et al. (1997). The $U_{\mathrm{p}}$ values measured for the final states were checked against those calculated by the impedance match method using the measured impact velocity because some fringes may have lost during the VISAR recording. If necessary, numbers were added to correct the final velocity, as listed in Table 2.

For shots at impact velocities of $1.28-1.89 \mathrm{~km} / \mathrm{s}$, they displayed single wave structures and fast risings in shots \#1381, 1382 and 1386, although some fringes were obviously lost and added to correct the velocity by the help of the impedance match calculation. This etalon setting with a low fringe per velocity constant was inevitable in order to observe the HEL. A rarefaction wave arrives $0.4-0.5 \mu$ s af- 
ter the compression wave. Figure 3 shows the relationships between $U_{\mathrm{s}}$ and $U_{\mathrm{p}}$ and between pressure and density for Kinosaki basalt, compared with the data from Nakazawa $e t$ al. (1997). The Hugoniot for Kinosaki basalt can be described by $U_{\mathrm{s}}=3.5+1.3 U_{\mathrm{p}}$ in the low-pressure plastic region, and the pressure-density curve does not indicate any discontinuity that appeared in the data by Nakazawa et al. (1997).

The partial release state from a Hugoniot state can be determined using the measured particle velocity in a window material. The volume change along the release isentrope can be obtained from the release path in the $P-U_{\mathrm{p}}$ plane (Zel'dovich and Raizer, 2002), known as the Riemann integral. In our measurements, only one intermediate release point was determined, corresponding to the state of window material. Figure 4 shows the Hugoniot of the Kinosaki basalt and the release or recompression state reflected by the window for the experiments that did not use a fused quartz window. The release and recompression states are closely on the Hugoniot, and it is clear from this result that the Hugoniot state is almost same as the isentropic state at these low shock pressures.

\section{Discussion}

There are two known examples of VISAR profiles for basalt at relatively weak pressures. Grady (2000) used Dresser basalt (density of $2.980 \mathrm{~g} / \mathrm{cm}^{3}, C_{l}$ of $6.05 \mathrm{~km} / \mathrm{s}$, $C_{s}$ of $3.51 \mathrm{~km} / \mathrm{s}$ ) and determined spall properties below the HEL. He suggested a HEL below several GPa for the basalt. Stewart et al. (2006) used Columbia River basalt (density of $2.83 \mathrm{~g} / \mathrm{cm}^{3}, C_{l}$ of $5.73 \mathrm{~km} / \mathrm{s}, C_{s}$ of $3.46 \mathrm{~km} / \mathrm{s}$ ) and measured the free surface velocity and thermal emission at 2 , 28.9, and $32 \mathrm{GPa}$. Their VISAR did not use a window and did not determine the HEL. Ahrens and Gregson (1964) determined a HEL of 4-5 GPa for Vacavill basalt (density of $2.82 \mathrm{~g} / \mathrm{cm}^{3}$ ) by the inclined mirror method and noted that elastic wave amplitudes decay with propagation distance. Nakazawa et al. (1997) determined the HEL for Kinosaki basalt according to their observed $U_{\mathrm{s}}-U_{\mathrm{p}}$ relation. Their method was indirect and may not distinguish between the elastic and plastic waves. In addition, there seems to have been an effect from the HEL originating from the metal flyer, resulting in unreliable estimation of the shock wave velocity. Our present VISAR study reveals the effect of HEL of metal, even if it is not high. We detected directly the two waves in the VISAR profiles and two-wave structures were observed at pressures below $12 \mathrm{GPa}$ for Kinosaki basalt. Kinosaki basalt has a relatively low density, and it is reasonable that the HEL for Kinosaki basalt is the lowest among the measured basalts.

The equation of state for rocks with basaltic compositions is summarized in Fig. 5. The $U_{\mathrm{s}}-U_{\mathrm{p}}$ relation for plastic wave at low pressures can be expressed by a linear relation of $U_{\mathrm{s}}=3.5+1.3 U_{\mathrm{p}}$ for a range of $U_{\mathrm{p}}$ between $\sim 0.3$ and $\sim 4 \mathrm{~km} / \mathrm{s}$. Trunin et al. (1988) gave a relation of $U_{\mathrm{s}}=3.35$ $+1.46 U_{\mathrm{p}}$ for a gabbro with $2.89 \mathrm{~g} / \mathrm{cm}^{3}$ at $U_{\mathrm{p}}$ from 1.8 to $4 \mathrm{~km} / \mathrm{s}$, which indicates a slightly higher shock velocity. All these data for the basaltic compositions indicate that there is no high pressure phase transition below $\sim 100 \mathrm{GPa}\left(\mathrm{a} U_{\mathrm{p}}\right.$ up to $\sim 4 \mathrm{~km} / \mathrm{s}$ ). Taking into account the data by Jones

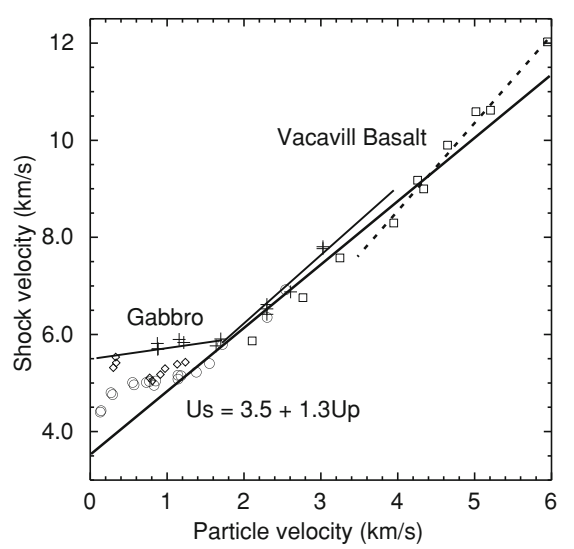

Fig. 5. Summary of shock velocity $\left(U_{\mathrm{s}}\right)$-particle velocity $\left(U_{\mathrm{p}}\right)$ relations for rocks with basaltic compositions. Vacavill basalt (initial density of $2.82 \mathrm{~g} / \mathrm{cm}^{3}$ ) data from Ahrens and Gregson (1964) (squares) and Jones et al. (1968) (diamonds); gabbro data from Marsh (1980) (crosses with initial density of $2.98 \mathrm{~g} / \mathrm{cm}^{3}$ ) and Trunin et al. (1988) (shown by thin solid lines, initial density of $2.89 \mathrm{~g} / \mathrm{cm}^{3}$ ); Kinoasaki basalt from Nakazawa et al. (1997) (circles with initial density of $2.87 \mathrm{~g} / \mathrm{cm}^{3}$ ). A bold line expressed by $U_{\mathrm{s}}=3.5+1.3 U_{\mathrm{p}}$ is given to represent the best approximation for the low pressure region. The Hugoniot elastic limits for basalts are estimated to be about $2-5 \mathrm{GPa}$. A broken line indicates the $U_{\mathrm{s}}-U_{\mathrm{p}}$ relation for Vacavill basalt in the high-pressure region.

et al. (1968), there seems to be a phase transition above $\sim 100 \mathrm{GPa}$.

In the relatively low-pressure region of basalt, the $U_{\mathrm{s}}$ $U_{\mathrm{p}}$ relations are complicated, because the material strength greatly influences the regime. The spall strength of a basalt has generally been measured to be about $130 \mathrm{MPa}$, corresponding to an impact velocity of $60 \mathrm{~m} / \mathrm{s}$ (Grady, 2000). Dynamic tensile strength of a basalt was also determined to be 157-179 MPa by a flat plate impact experiment (Cohn and Ahrens, 1981). Ultrasonic measurements of postimpact gabbro indicated a tensile stress $(\sim 150 \mathrm{MPa})$ for the onset of tensile failure (Ai and Ahrens, 2004). The yield strength of Kinosaki basalt at HEL can be calculated to be $\sim 1.5 \mathrm{GPa}$ from the determined HEL (Meyers, 1994), and it is about tenfold greater than the tensile stress. A similar conclusion was drawn from the laser shock experimental results on Peats Ridge basalt, NSW in Australia (density of $2.9 \mathrm{~g} / \mathrm{cm}^{3}$, bulk sound velocity of $5.68 \mathrm{~km} / \mathrm{s}$ ) (Bolger et al., 1999). These researchers showed an unconfined compression strength of $300 \mathrm{MPa}$ and a tensile strength of $30 \mathrm{MPa}$. These stress levels can be taken into account to model collision and fracture of basaltic bodies at the time of impact events, when we have to apply a proper scaling rule (e.g. Mizutani et al., 1990).

Acknowledgments. We thank Sara Stewart and an anonymous reviewer for their comments and suggestions to improve this draft. This study was supported in part by the Grant-in Aid for scientific research by JSPS (No. 18204051).

\section{References}

Ahrens, T. J. and V. G. Gregson, Shock compression of crustal rocks: data for quartz, calcite, and plagioclase rocks, J. Geophys. Res., 69, 48394874, 1964.

Ai, H. A. and T. J. Ahrens, Dynamic tensile strength of terrestrial rocks and application to impact cratering, Meteor. Plan. Sci., 39, 233-246, 2004.

Barker, L. M., The accuracy of VISAR instrumentation, Shock Comp. 
Cond. Matter-1997, 833-836, 1998.

Barker, L. M. and R. E. Hollenbach, Laser interfemometer for measuring high velocities of any reflecting surface, J. Appl. Phys., 43, 4669-4675, 1972.

Basaltic Volcanism Study Project, Basaltic Volcanism on the Terrestrial Planets, 1286 pp, Pergamon Press, New York, 1981.

Bolger, J. A., C. S. Montross, and A. V. Rode, Shock waves in basalt rock generated with high-powered lasers in a confined geometry, J. Appl. Phys., 86, 5461-5466, 1999.

Cohn, S. N. and T. J. Ahrens, Dymanic tensile strength of lunar rock types, J. Geophys. Res., 86, 1794-1802, 1981.

Genbudo Research Group, Geology and petrology of quaternary volcanic rocks from the Genbudo area, northern Hyogo prefecture, southwest Japan-Genbudo and Akaishi lavas—, Earth Sci., 45, 131-144, 1991 (in Japanese with English abstract).

Grady, D. E., Spall properties of Solenhofen limestone and Dresser basalt, Shock Comp. Cond. Matter-1999, 1255-1258, 2000.

Holmes, N. C. and E. F. See, Shock compression of low-density microcellular materials, Shock Comp. Cond. Matter-1991, 91-94, 1992.

Jones, A. H., W. M. Isabell, F. H. Shipman, R. D. Perkins, S. J. Green, and C. J. Maidon, Material properties measurements for selected materials, Inter. Rep. NAS2-3427, GE Tech. Center, Michigan, 1968.

Marsh, S. P., LASL Shock Hugoniot Data, University of California Press, 1980.

Meyers, M. A., Dynamic Behavior of Materials, 183 p, John Wylie \& Sons, New York, 1994.
Mizutani, H., Y. Takagi, and S. Kawakami, New scaling laws on impact fragmentation, Icarus, 87, 307-326, 1990.

Nakazawa, S., S. Watanabe, M. Kato, Y. Iijima, T. Kobayashi, and T. Sekine, Hugoniot equation of state of basalt, Planet. Space Sci., 45, 1489-1492, 1997.

Nakazawa, S., S. Watanabe, Y. Iijima, and M. Kato, Experimental investigation of shock wave attenuation in basalt, Icarus, 156, 539-550, 2002.

Nikolaev, D. N., V. E. Fortov, A. S. Filimonov, S. V. Kvitov, and V. Ya. Ternovoi, $\mathrm{SiO}_{2}$-aerogel plasma properties in the energy range up to 65 kJ/g, Shock Comp. Cond. Matter-1999, 121-124, 2000.

Stewart, S. T., G. B. Kennedy, L. E. Senft, M. R. Furlanetto, A. W. Obst, J. R. Rayton, and A. Seifter, Post-shock temperature and free surface velocity measurements of basalt, Shock Comp. Cond. Matter-2005, 14841487, 2006.

Trunin, R. F., G. V. Simakov, I. P. Dudoladov, G. S. Telegin, and I. P. Trusov, Rock compressibility in shock waves, Izv. Earth Phys., 24, 3842, 1988.

Van Thiel, M., Compendium of Shock Wave Data, UCRL-50108, Vol. 3, 721-725, 1977.

Zel'dovich, Y. B. and Y. P. Raizer, Physics of Shock Waves and HighTemperature Hydrodynamic Phenomena, 916 pp, Dover, New York, 2002.

T. Sekine (e-mail: SEKINE.Toshimori@nims.go.jp), T. Kobayashi, M. Nishio, and E. Takahashi 